\title{
Quality control and assurance in fabrication of welded structures subjected to fatigue loading
}

\author{
T. Stenberg ${ }^{1}$ - Z. Barsoum ${ }^{1}$ (D) - E. Åstrand ${ }^{2} \cdot$ A . Ericson Öberg ${ }^{2} \cdot$ C. Schneider ${ }^{3}$. \\ J. Hedegård ${ }^{3}$
}

Received: 5 December 2016 / Accepted: 29 May 2017 /Published online: 28 June 2017

(C) The Author(s) 2017. This article is an open access publication

\begin{abstract}
The current paper presents a comprehensive overview of weld quality control and assurance of welded structures where the major failure prevention is due to fatigue loading. It gives the drawbacks and limitation of quality control systems, international weld quality standards, and guidelines used in today's weld production. Furthermore, in recent development in quality control and assurance of welded structures, a new online method is presented. The main target is to enable a complete, online evaluation of large quantities of welds in an accurate and repeatable fashion. Information gathered will not only be used for determining the weld quality level with respect to the fatigue strength but also to be evaluated for use in improved process control, in welding power sources, and robot control systems. It is verified that the new online method, a new laser scanning technology, and algorithms can successfully be used as modern tools for automated unbiased geometrical weld quality assurance and implemented in weld production environment.
\end{abstract}

Keywords (IIW Thesaurus) Welded joints · Imperfections · Fatigue $\cdot$ Quality $\cdot$ Surface measurements $\cdot$ Inspection

Recommended for publication by Commission XIII - Fatigue of Welded Components and Structures

Z. Barsoum zuheir@kth.se

KTH Royal Institute of Technology, Stockholm, Sweden

Volvo Construction Equipment AB, Eskilstuna, Sweden

Swerea KIMAB AB, Kista, Sweden

\section{Introduction}

Steel is the dominating material for many types of load carrying structures and components in construction machineries, loader cranes, forestry machines, mining equipment, transport vehicles, and agricultural equipment. Normally, $60-80 \%$ of the vehicle weight consists of steel plates and steel castings in thickness $6-70 \mathrm{~mm}$ with welding as the primary joining technology. Structural details in trucks, buses, and trains are also often manufactured using different welding technologies. Thus, a large part of the products being used in the global transport system often consists of heavy steel structures where welding is a dominating joining technology. Structural details and components in many of these products are continuously subjected to variable loading during operation. Typically, a load range for many types of vehicles and machineries is 1000-20,000 cycles per $h$. This means that during the economic life of 10,000-25,000 operation hours, the components will sustain 10-500 million load ranges. Thus, fatigue loading is the most common failure mode for the abovementioned products.

Material and fabrication technologies for welded structures are continuously developing. The end users are also continuing to push the limits of the structures used in automotive, construction, offshore, energy production, and within many other fields. The endeavors to reduce weight and cost, increase energy efficiency, improve performance, and reduce the environmental impact continue to provide challenges in fatigue design of welded structures. Structures which incorporate welding of high-strength materials also require a fundamental understanding of potential failure modes and mechanisms. In order to enable the production of more lightweight structures, the utilization of high-strength materials is increasing rapidly. However, when designing a welded structure in high-strength steel, the designer needs to consider several important factors 
in order to allow for the lightweight potential, i.e., to reduce the scatter of quality in production and at the same time increase the weld quality.

Fatigue failures in welded structures often starts in the welded joint where the fatigue strength is generally lower compared to base material and notched components, see Fig. 1a. The fatigue life in base material and notched components is dominated by the crack initiation phase; however, in welded structures, most of the propagation phase is consumed due to defects and imperfections which are induced during the welding process. There is a great scatter in fatigue life of welded joints which is mainly due to the variation of the local weld geometry, size, and location of defects and residual stresses initiated during the welding process. This has been verified in multiple studies, and it has been incorporated in weld quality standards and recommendations for fatigue design of welded joints [1, 2]. Since defects, imperfections, and other types of irregularities are common in welds, it becomes important to have rules and acceptance criteria for them. These weld defects determine the fatigue life which is supported by the Kitagawa diagram, Fig. 1b, which shows the fatigue strength versus defect size at various locations in the weld joint [6]. The weld class system describes many kinds of
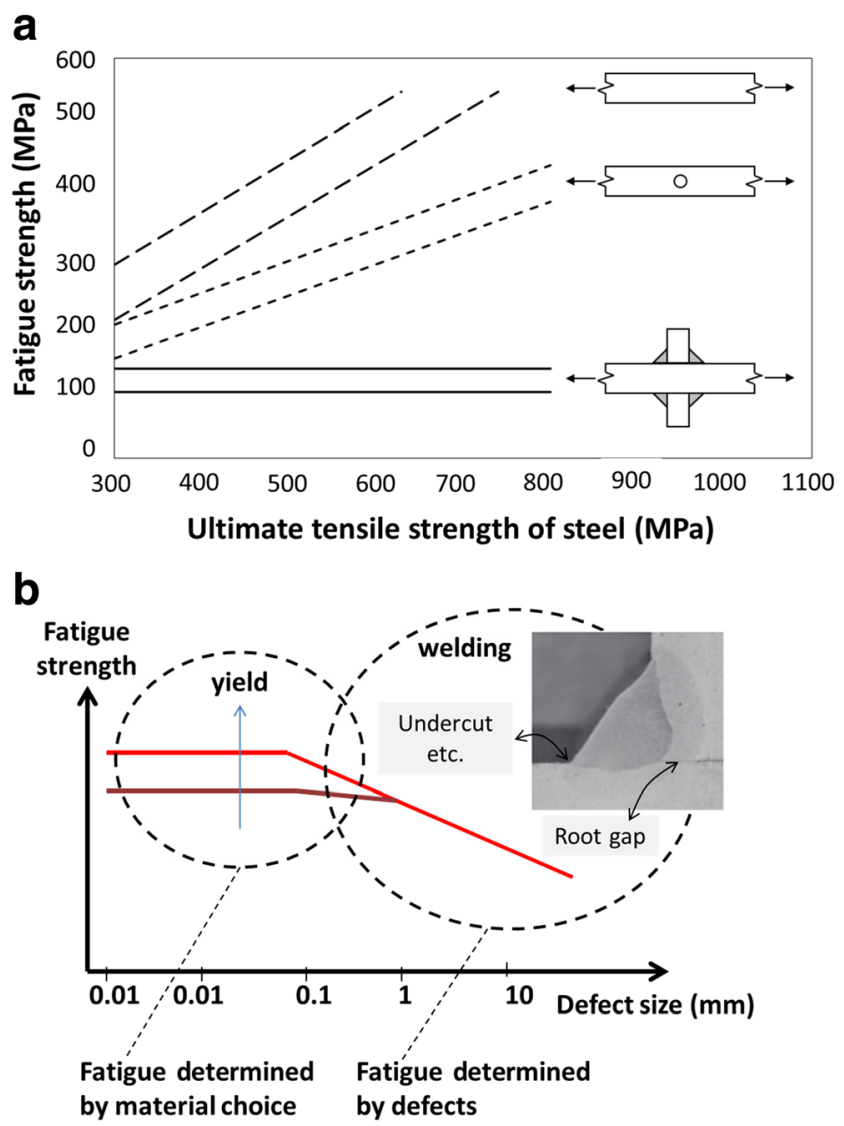

Fig. 1 a Schematic illustration of fatigue strength in base material and notched and welded components. b Kitagawa diagram, fatigue strength versus defect size, with indicated weld positions [6] imperfections and states the acceptance limits for various levels of quality, e.g., ISO 5817 [3], having the classes D, C, and $\mathrm{B}$ where $\mathrm{B}$ has the highest weld quality and $\mathrm{D}$ the lowest. However, current rules given in this system show a week relation to fatigue, which has been proven in several investigations $[4,5]$. Consequently, if the designers use this system to reduce the weight of a load-carrying structure and optimize plate thicknesses along with the weld geometry for fatigue, they meet the problem of how to decide the appropriate quality expressed as the weld quality level.

Design and manufacturing of welded structures are important tasks which require accuracy, especially for robotic welding in serial production. For lightweight welded structures, however, where thinner and high-strength steels are utilized, the increased nominal stress levels require consideration of other design aspects such as buckling, plastic collapse, and fatigue strength. High-strength steels suffer from an increased sensitivity to notches and defects compared to mild steels. For welded components, the fatigue strength will be the same for high-strength steel and mild steel if no improved weld quality is achieved [6]. Thus, improving the design of the welded structure by using high-strength steel requires improved weld quality, which in turn demands an improved quality assurance. Today, most of the quality assurance for welded components is carried out by the audit process, separate to the production line, using standard handheld gauges. Hammersberg and Olsson [7] concluded that basic standard gauges and methods for weld quality assurance are out-dated if care is not taken to investigate and improve the used measurement systems relative to the actual variations occurring in production. Thus, to fully achieve lightweight design in welded structures, manufacturing companies which utilize serial production will face challenges in quality assurance when introducing highstrength steel in their products. Other methods and tools which can be used for assessing the weld surface geometry are laser profile sensors or vision systems, in which the scanning device is used to acquire the surface and then an algorithm calculates certain surface features of the welded joint being measured [8-10].

This current study gives a brief description of how to define weld quality, different weld quality systems for weld quality control, and assurance for welded structures subjected to fatigue loading. Furthermore, it brings light into aspects that are important for quality assurance of welded structures and how welds could be designed and fabricated for a purpose. Finally, a new online method is presented for unbiased geometrical weld quality assurance, which is successfully verified with testing. The focus of this study is to cover aspects of outer shape of the weld geometry; hence, internal aspects such as penetration and lack of fusion are not covered.

Design and manufacturing of welded structures are important tasks which require accuracy, especially for robotic welding in serial production. For lightweight welded 
structures, however, where thinner and high-strength steels are utilized, the increased nominal stress levels require consideration of other design aspects such as buckling, plastic collapse, and fatigue strength. High-strength steels suffer from an increased sensitivity to notches and defects compared to mild steels. For welded components, the fatigue strength will be the same for high-strength steel and mild steel if no improved weld quality is achieved [6]. Thus, improving the design of the welded structure by using high-strength steel requires improved weld quality, which in turn demand an improved quality assurance. Today, most of the quality assurance for welded components is carried out by the audit process, separate to the production line, using standard gauges. Hammersberg and Olsson [7] concluded that basic standard gauges and methods for weld quality assurance are outdated if care is not taken to investigate and improve the used measurement systems relative to the actual variations occurring in production. Thus, to fully achieve lightweight design in welded structures, manufacturing companies which utilize serial production will face challenges in quality assurance when introducing high-strength steel in their products.

This current study gives a brief description of different weld quality systems for weld quality control and assurance for welded structures subjected to fatigue loading. Furthermore, it brings light into aspects that are important for quality assurance of welded structures and how welds could be designed and fabricated for a purpose. Finally, a new online method is presented for unbiased geometrical weld quality assurance, which is successfully verified with testing and implementation in weld production environment.

\section{Weld quality standards}

The weld quality quantifies the welded joints' ability to perform the functional requirements of the weld during the service life of the structure. This could be either durability in static and/or dynamic loading, corrosion resistance, appearance, or any other mechanical function. Insufficient quality must be avoided due to profound consequences in safety and cost, i.e., failure occurs at an early stage. Excessive quality on the other hand may result in increased fabrication cost which does not add more customer value to the product. It is also necessary as a design engineer to specify the sufficient quality in the relevant locations of the structure, as various locations in the structure may experience increased loading due to local stress raisers such as stiffeners, holes, and notches [6]. The geometry of the weld depends on several factors such as weld filler material, orientation of the work piece during welding, and process parameters [11-13]. Also, different weld discontinuities and geometrical imperfections affect the fatigue life of the welded joint differently. An efficient fabrication of welded structures requires a quality system to work with.
This should support best practice and give predicted fatigue life properties of the structures. The weld requirements are the most important factors in the quality system which determines both fabrication cost and the fatigue life.

In a comparison of six international and national standards for welding quality criteria, demands are in general based on workmanship rather than fatigue properties. One standard applies to fitness for purpose, but this standard is used for nuclear power plants and is not widespread [14].

\subsection{International standard SS-EN ISO 5817}

SS-EN ISO 5817 is a European standard for fusion welded joints in steel, nickel, titanium, and their alloys with quality levels and imperfections [3]. The weld quality is defined by quality levels (B, C, or D), where B is the highest and D the lowest weld quality, respectively. The letters represent different quality levels with acceptance limits defined for each weld discontinuity and imperfection. The standard covers more than 40 different discontinuities and weld imperfections for the different quality levels; Fig. 2 presents some of these discontinuities. The ISO 5817 standard was designed in the 1960s using a German standard DIN 5863, by welding workshops which were following the principle of "good workmanship." Many requirements lack a connection to fatigue and are unnecessary demanding, like overlap and excess weld metal. Other requirements are too generous like, incompletely filled groove, or linear misalignment and can ruin the fatigue life if they are present. In an ideal welding standard, there should be a clear and consistent connection; assuring that a certain welding quality level always results in a certain fatigue life of the welded joint.

Karlsson and Lenander [5] conducted a comprehensive study of the relation between the acceptance limits within ISO 5817 and the resulting fatigue life using fracture mechanics. It was shown that for some imperfections, there was a direct relationship between the acceptance limit and the resulting fatigue life, i.e., a higher quality level should result in longer fatigue life compared to a lower quality level. However, this was not consistent for all discontinuities, where several shows little or no relationship between the quality level and the fatigue life. Figure 3 gives examples of discontinuities which have poor correlation between weld quality and fatigue life (1.10 excessive convexity and 1.16 unequal leg length) and good correlation (1.17 root concavity and 3.2 angular misalignment), respectively. One of the most critical local weld geometry features is the weld toe radius $[13,15,16]$ which is vaguely regulated by acceptance limits with a simple requirement of smooth transition. One of the reasons is that until presently, it has been difficult to quantify the weld toe radius accurately and robustly. Instead, ISO 5817 gives acceptance level for the weld toe angle.

At the current state, the designers have no other choice than to assume average fatigue strength due to missing guidelines 
Fig. 2 Examples of weld discontinuities covered in SS-EN ISO 5817 [3]

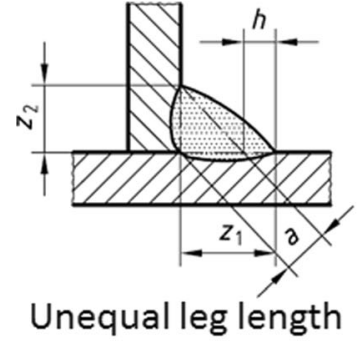

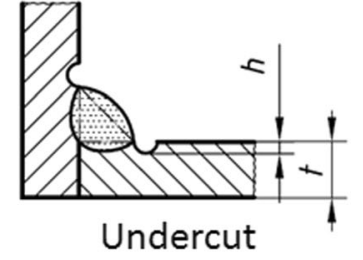

Undercut

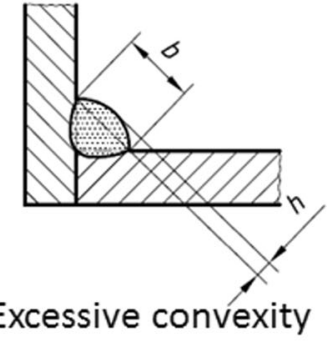

(fillet weld)

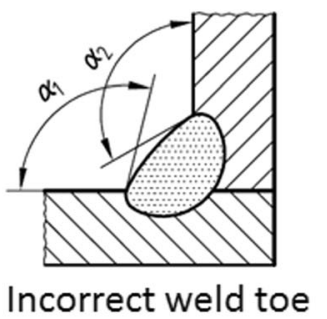

(fillet weld)

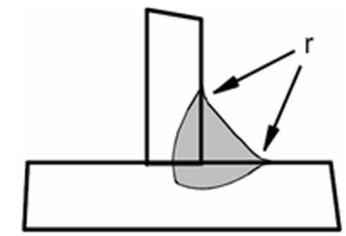

"Smooth weld transition" for high quality in production and absent instructions for taking advantage of the high-quality welds in the design [17]. In the current version of ISO 5817, an annex has been added for additional requirements for welds in steel subjected to fatigue which is based on Volvo Group STD 181-0004 [1]. In particular, it relates the weld quality levels to the fatigue strength and gives acceptance limits for the different weld quality levels based on, e.g., the weld toe radii.

\subsection{Volvo Group STD 181-0004}

A new weld quality standard was introduced by Volvo Group [1] in 2008 with quality levels with relation to the fatigue strength. The new weld quality system [1] is divided into four different quality levels (VE, VD, VC, VB) for fatigue loaded structures and one for static loaded structures (VS). Quality level VE, which has the lowest requirements regarding discontinuities, should be used for welds where the root and weld penetration is critical.

VD and VC stands for the "as welded condition," normal quality (VD) and high quality (VC). The last and highest level (VB) stands for "post treated welds" regardless of kind of treatment. The quality system defines rules for imperfections on the surface and embedded. The weld root is not considered in the quality system and should be a dimension on the drawing. One important feature in the weld quality system is that the acceptance limits reflect the fatigue life, and those imperfections which do not have an impact on the fatigue life are not

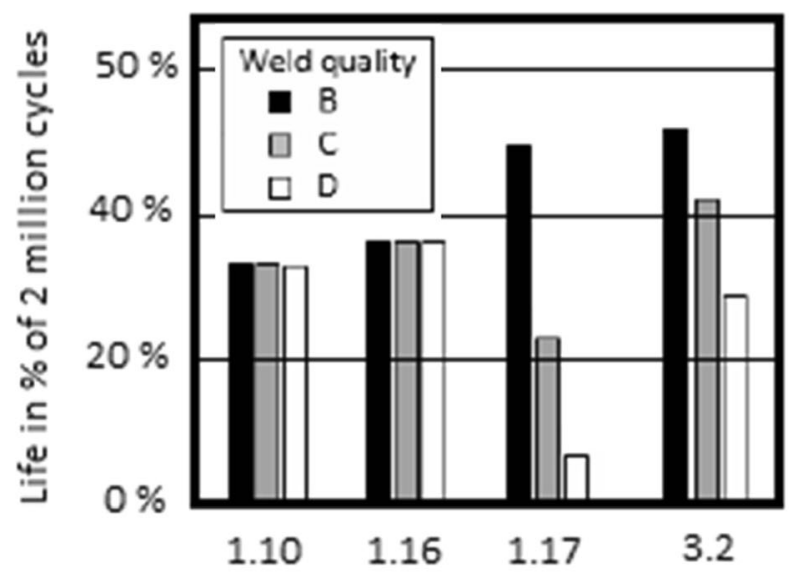

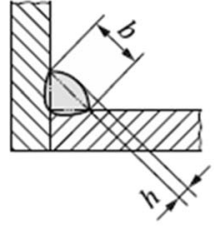

1.10 Excessive convexity
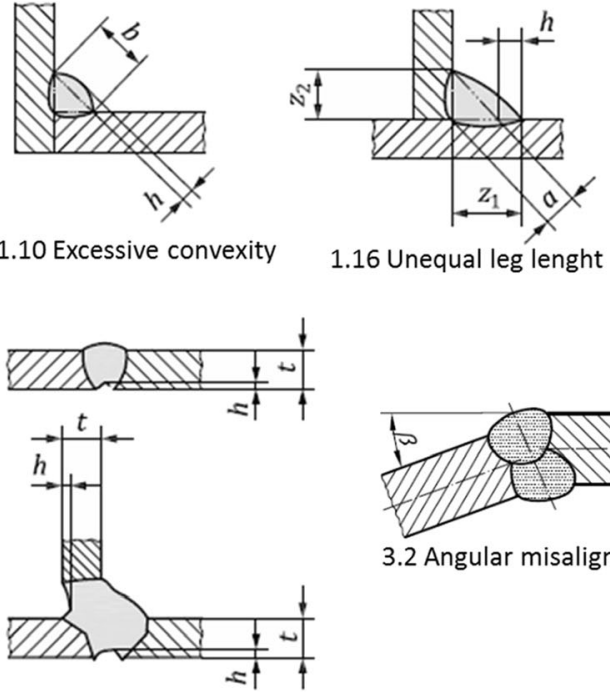

1.17 Root concavity

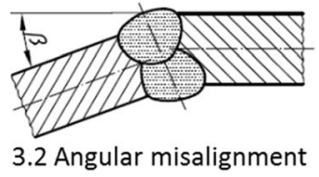

Fig. 3 Example of relation between weld quality acceptance limits in ISO 5817 and the resulting fatigue life [1] 
included. If the quality level is increased one step, the fatigue life should be expected to increase a factor of 2 or alternatively the allowed stress level could be increased by $25 \%$. Example of acceptance limits for different discontinuities in STD 1810004 is given in Table 1.

\subsection{IIW guidelines on weld quality}

The International Institute of Welding (IIW) have recently published a Guideline on weld quality in relation to fatigue strength [18] with the intention to provide quantitative and qualitative measures of geometric features and imperfections of welded joints to ensure that it meets the fatigue strength demands found in IIW [2] based on different assessment methods $[2,19,20]$. It also defines acceptance criteria based on weld geometry and imperfections which results in increased fatigue strength which are defined in S-N curves for different fatigue assessment methods.

\section{Design and weld for purpose}

The overall trend nowadays is to develop, design, and fabricate optimized cost-effective welded structures which should consider the aspects of the material, production, and dimensioning methods to achieve the objectives concerning weight, quality, and cost, which often are contradictory. Therefore, it is important to consider the purpose of the weld and to "design for purpose." This means that the weld should be dimensioned so that it can carry the load it is subjected to, see Fig. 4. This would mean that if the joint is subjected to the load $F_{1}$, the weld root would be the critical location of the welded joint assuming partial penetration and an ordinary throat thickness. If the throat thickness is very large compared to the plate thickness, the weld toe can be critical. When the joint is

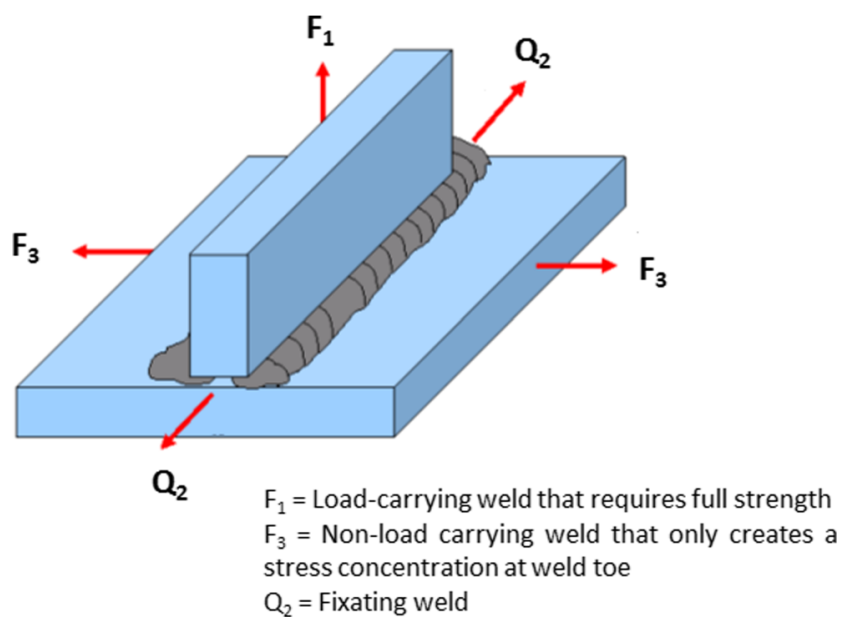

Fig. 4 Example of how to categorize weld based on the loading

subjected to the load $F_{3}$, the weld toe is critical. This should be considered when dimensioning the weld in order to have the correct weld quality requirements. The easiest scenario would be the load $Q_{2}$, where the load results in shear stress in the weld, hence a loss in shear strength capacity.

There are still some problems connected to the weld quality systems in relation to the desired principle to have different welding procedures for various load conditions. The weld classes are inexplicit, and it is then hard to specify different requirements according to the load. This leads to a situation where many or most of the specified requirements are not relevant to the fatigue strength of the joint while other significant demands are not stated at all or drowned among all other requirements. This is visualized in Fig. 5. The welder or robot programmer has to follow the standard even though the fatigue life could be increased and the production cost reduced with optimized requirements. The most important geometrical parameters of the welds are the notch radius in the weld toe and depth of penetration in the root [18]. The discrepancy

Table 1 Example of acceptance limits for quality level in STD 181-0004 [1]

\begin{tabular}{|c|c|c|c|c|c|}
\hline $\begin{array}{l}\text { Discontinuity types } \\
\text { Weld class for }\end{array}$ & $\begin{array}{l}\text { VS } \\
\text { Static strength }\end{array}$ & $\begin{array}{l}\text { VE } \\
\text { Fatigue strength }\end{array}$ & VD & $\mathrm{VC}$ & VB \\
\hline Cold lap & Permitted & $a \leq 1 \mathrm{~mm}$ & $a<0.5 \mathrm{~mm}$ & $a<0.1 \mathrm{~mm}$ & Not permitted \\
\hline Internal lack of fusion & $a \leq 0.2 \mathrm{t}$ & Not permitted & Not permitted & Not permitted & Not permitted \\
\hline $\begin{array}{l}\text { Weld toe transition } \\
\text { radius }\end{array}$ & No requirements & No requirements & $R>0.3 \mathrm{~mm}$ & $R>1 \mathrm{~mm}$ & $R>4 \mathrm{~mm}$ \\
\hline Undercut $^{\mathrm{a}}$ & $a \leq 0.2 \mathrm{t}[\max 2.0 \mathrm{~mm}]$ & $a \leq 0.1 \mathrm{t}[\max 1.0 \mathrm{~mm}]$ & $a<0.05 \mathrm{t}[\max 1.0 \mathrm{~mm}]$ & $a<0.04 \mathrm{t}[\max 1.0 \mathrm{~mm}]$ & Not permitted \\
\hline $\begin{array}{l}\text { Underpassed } \\
\text { throat dimension }\end{array}$ & $a \geq 0.8 \mathrm{a}$ & $a \geq 0.9 \mathrm{a}[\max 2.0 \mathrm{~mm}]$ & $a \geq 0.9 \mathrm{a}[\max 2.0 \mathrm{~mm}]$ & Not permitted & Not permitted \\
\hline $\begin{array}{l}\text { Edge displacement } \\
\text { (linear } \\
\text { misalignment) }\end{array}$ & $a \leq 1.5 \mathrm{t}+0.25 \mathrm{t}[\max 5.0 \mathrm{~mm}]$ & $a \leq 1.0 \mathrm{t}$ & $a<0.1 \mathrm{t}$ & $a \leq 0.05 \mathrm{t}$ & Not permitted \\
\hline
\end{tabular}

${ }^{a}$ Valid for butt welds, higher acceptance limits for fillet welds

$a$ throat thickness (mm)

$t$ plate thickness $(\mathrm{mm})$ 
Fig. 5 Critical positions in a fillet for different load condition, illustrating the concept of weld for purpose
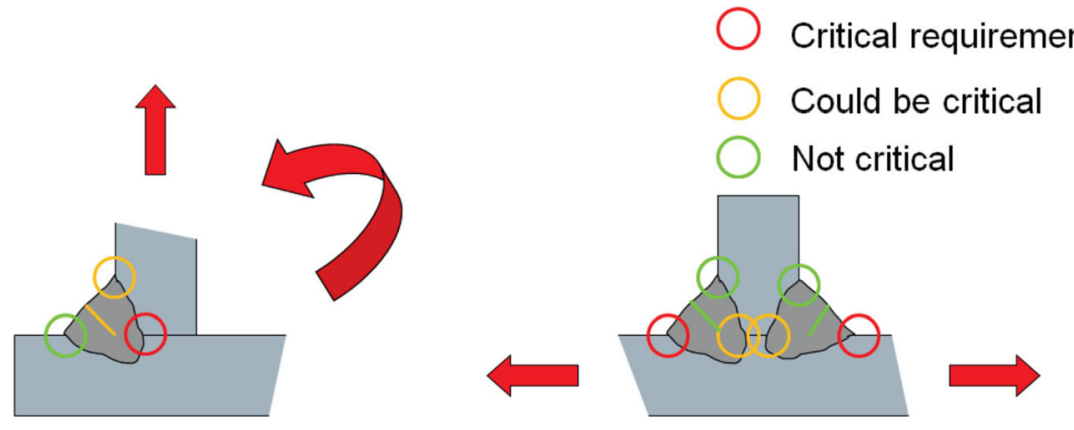

between the requirements and the structural integrity may give rise to problems and unnecessary cost in the weld shop. Typically, the weld size and quality level are similar for all load conditions, meaning that same welding procedures are used. These results give a misdirected focus were the welder do not consider the critical characteristics of the weld before any other requirement. All requirements are getting the same attention, according to good workmanship, while many of them do not add any value to the customer regarding structural integrity. In the worst case, fulfillments of non-critical requirements are done on behalf of the critical characteristic [21]. Studies show a contradiction between large throat size and extensive weld penetration, meaning that it can be beneficial to specify and aim for a smaller throat size and receive a deeper penetration and by that an improved fatigue strength $[18,19]$. The welding standard has a high influence on the cost and a review which only states that the critical requirements of the weld can reduce the cost and increase the quality.

\section{Measurement systems for quality assurance of the weld surface geometry}

Today, numerous handheld manual gauges are available to assess the weld quality in production and inspection, see Fig. 6 . The gauges for measuring the weld toe radius are the radius gauge and the radius master, Fig. $6 a$, b. The radius gauge contains a set of blades where the end of every blade has a predefined radius. The measuring operation is performed manually, where the operator compares different blades with the weld toe radius being assessed. The weld toe radius is determined as the radius of the blade which has the best fit. The radius master is manufactured from a solid block using electrical discharge machining to achieve a high precision surface geometry, $\pm 0.03 \mathrm{~mm}$. The master resembles a welded cruciform joint where the four different sides contain a weld toe radius which correlates to the requirements within the weld quality system [1]. The measuring is conducted by visual inspection of the weld toe on the specimen being assessed. Using the radius master as a reference, the operator estimates the weld toe radius based on the visual difference between the specimen and the radius master.

When using a single manual gauge - or even an automated measurement system-for repeated measurements on a part, there will be a scatter or variation in the results. The variability in the measurement system can be investigated by conducting a measurement system analysis. Depending on the type of measurement data, Gauge $R \& R$ can be used. In that case, several operators conduct repeated measurements on several parts. The statistical analysis can then determine which part of the measurement system contributes the most to the variation: the gauge, the operator, or the measured parts. It is desired that the major source of the variation is the part-to-part variation, meaning that the variation stems from actual differences between the parts. To decide whether a gauge is appropriate for quality assurance or not depends on (i) what feature the system is supposed to measure, (ii) the specified tolerance width of that feature on the part, and (iii) if the gauge's contribution to the variation is
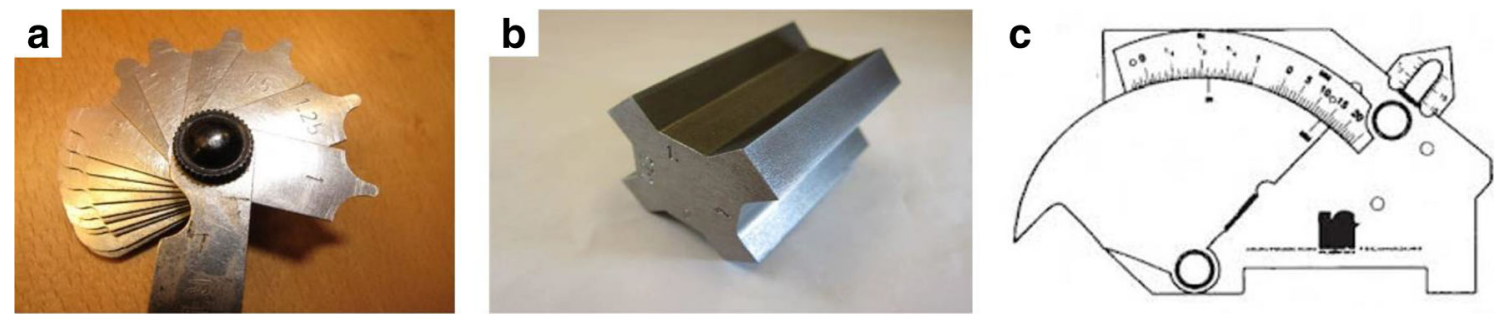

Fig. 6 Gauges for measuring the local weld geometry. a Radius gauge. b Radius master. $\mathbf{c}$ Gauge for throat thickness and depth of undercut 

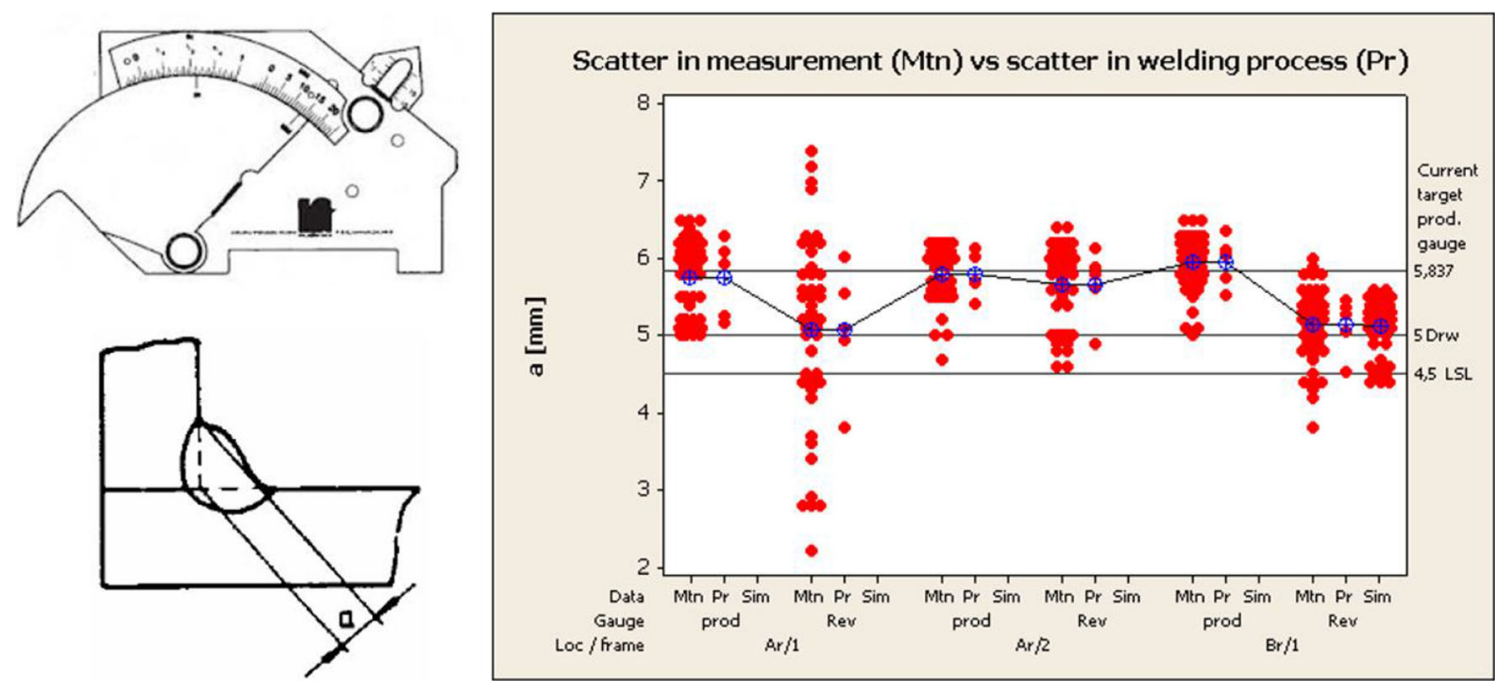

Fig. 7 Measurement system analysis of gauge for measuring the throat thickness [7]

significantly lower than the tolerance width of the part. If the feature is measured in the millimeter range, a rule of thumb is that the measurement system should be able to measure in the $1 / 10 \mathrm{~mm}$ range. A standard requirement is that for making Go/No Go decisions, the measurement system should not contribute more than $9 \%$ of the total variation in measurements. For process development, the contribution should be $<4 \%$ [7]. Hammersberg and Olsson [7] conducted a measurement system analysis on the gauge in Fig. 6c when measuring the weld throat thickness, see Fig. 7. It was concluded that the gauge had a contribution of almost $60 \%$ of the total variation, which is too large for Go/No Go decisions (>9\%) and process development $(>4 \%)$.

The gauges mentioned above are only able to measure on one single position at a time. Performing such an inspection is, therefore, time-consuming and subjective, which makes these gauges inappropriate for a lean, tact-timed production environment where the fast feedback of continuously changing local weld geometry is required.

Other tools available for measuring the local weld geometry are vision systems, where the welded surface is scanned, and the evaluation is performed in a computerized environment. The assessment is done by manually placing measurement points - a minimum of 3 -in the area of interest on the cross-section curve of the measured surface. The program then calculates the radius using the least square method, see Fig. 8. Thus, it is the operator who decides where the program calculates the weld toe radius and does the judgment if the radius fit is right or not. An equivalent way to measure radiuses is to do a weld impression analyze (WIA). For this measure, a dental impression material is used to create a replica of the weld surface. The impression is sliced in thin sections, and the measurement is done on a microscope picture in a computer with from the section, where a 3-point circle is drawn and measured on the weld toe transition. Gauge R\&R analyses

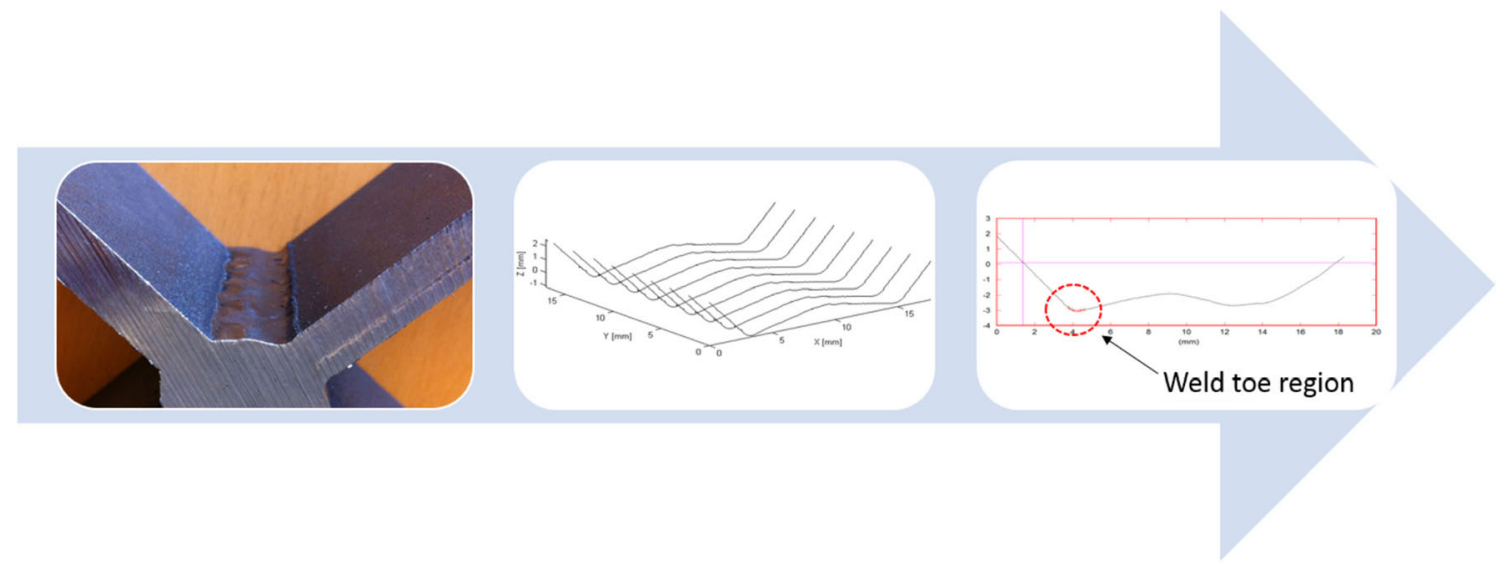

Fig. 8 Welded surface is measured and divided into several cross sections where each cross section is evaluated individually 
Fig. 9 ONWELD system; laser profile sensor, position coordinate scanning, and robot
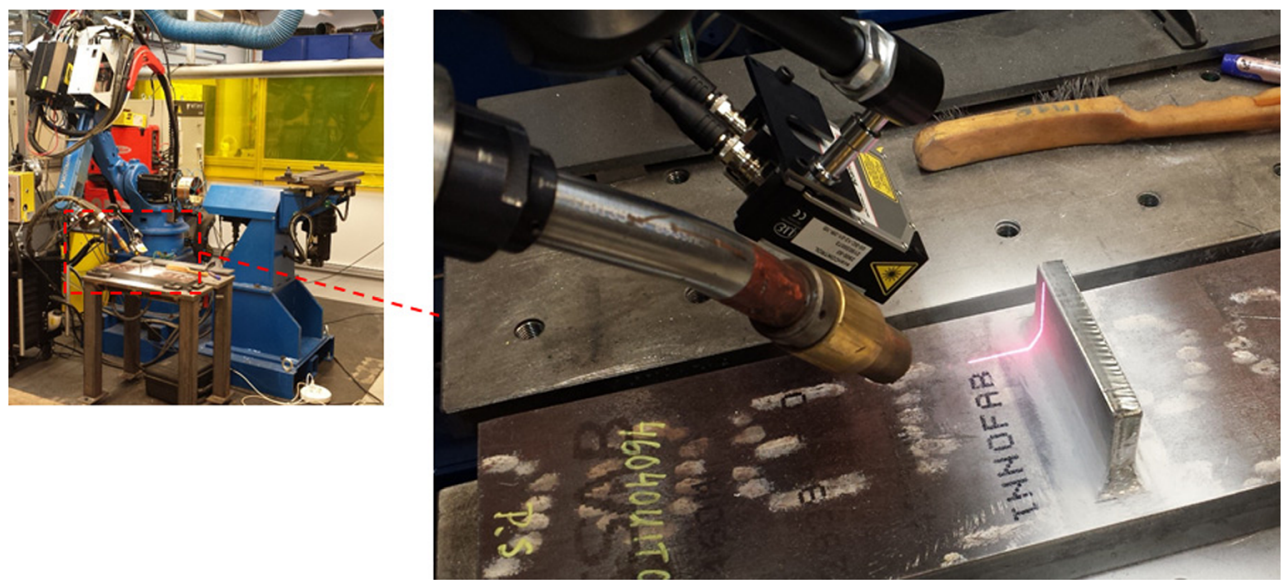

show excellent results for WIA where only $2 \%$ of the variation relates to the measurement system [22].

It is needed to know who want to make a decision and what type of information support is then necessary to choose the right measurement system. Ericson Öberg and Hammersberg describe different scenarios depending on the information need of the welder, programmer, or engineer [23, 24]. Depending on the information need, different methods for measuring weld toe radius are suitable. Unrelated to methods, standardized measure procedures which can be instructions or programmed algorithms are important.

\section{ONWELD—ONline WELD quality assurance}

As discussed in Sect. 1, the resulting fatigue strength of joints welded with high-strength steel is entirely dependent on the produced weld quality. This prevents designers to introduce high-strength steel in their welded components unless production departments have the necessary tools for quality assurance in serial production. These tools should result in online monitoring and control of the weld quality for real-time control and feedback on the quality produced. This will result in minimizing final inspection, audit, and repair, thus enabling cost-effective weld production and optimized lightweight welded structures with desired structural performance, e.g., in relation to fatigue.

Such a system has been developed, ONline method for quality assurance of WELDed structures (ONWELD), where concepts for quality measurements [6] have been implemented in a robotic cell. Figure 9 shows a picture of the complete system. A laser profile sensor is mounted on the robot head to scan the welded surface. Position coordinates of where the scanning is conducted are also acquired. The measured data is then sent for analysis, and the resulting weld geometry is presented to the operator in quantitative terms such as throat thickness, depth of undercut, and weld toe radius. The operator can also choose which quality standards (e.g., ISO 5817, STD 181-0004) should be used to check the acceptance limits against. Furthermore, the operator can specifically select which defect type/property that needs to be assessed and at what quality level, with respect to the acceptance limits. The properties that can be monitored with the system are throat size, transition radii, leg deviation, plate angles, and undercut size. This is illustrated in Fig. 10. The output will then be presented on a "Go/No Go" bar for the individual imperfections selected for evaluation over the measured distance. A "Go" would mean that the weld is satisfying the weld quality levels defined for the imperfection, and a

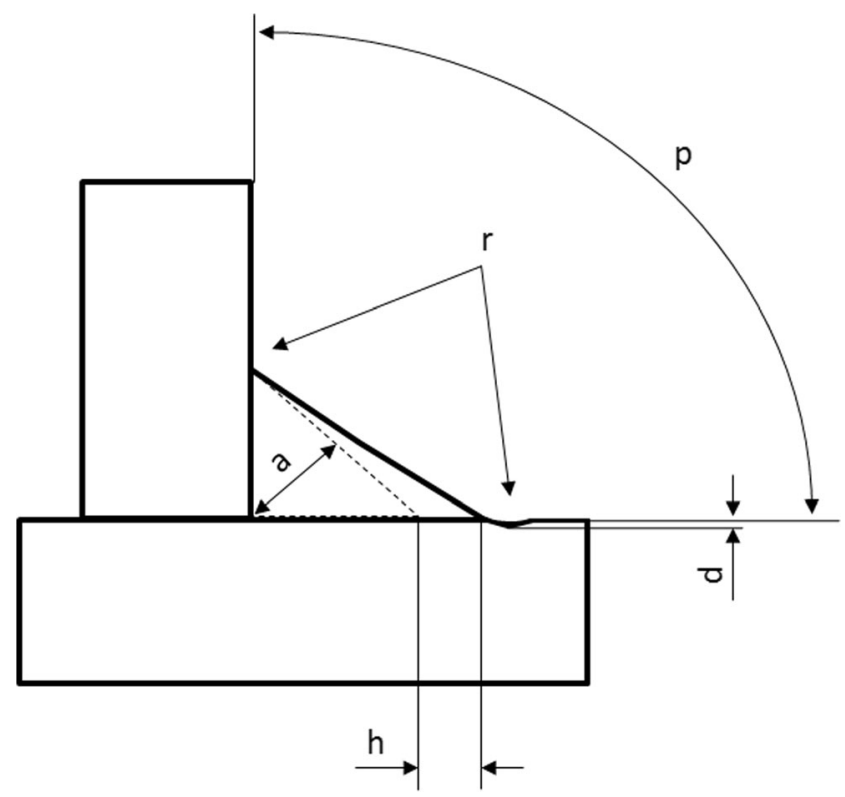

Fig. 10 Illustration of the properties/imperfections inspected: throat size $(a)$, transition radius $(r)$, leg deviation $(h)$, plate angle $(p)$, and undercut $(d)$ 


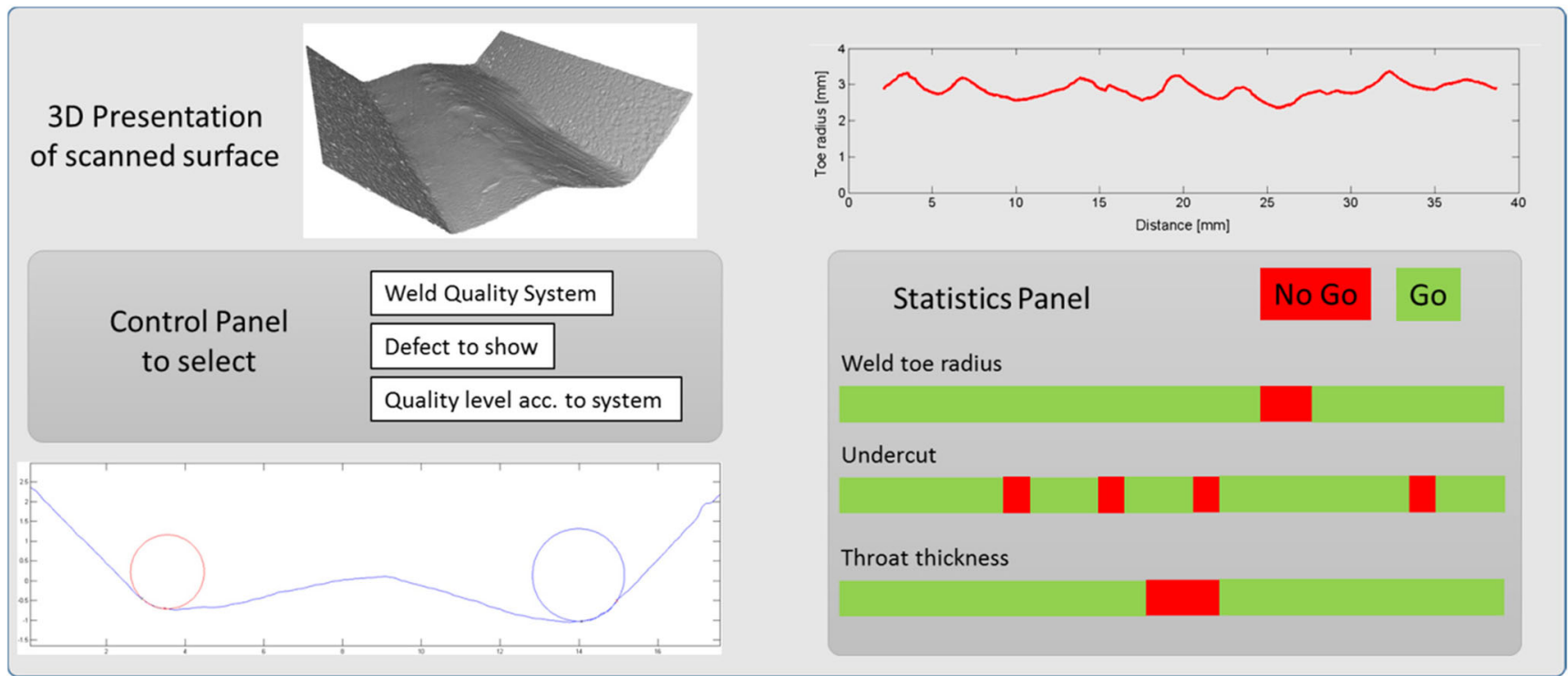

Fig. 11 GUI for the ONWELD system

"No Go" means that the requirements are not met and actions are necessary to either improve the weld quality or if applicable to downgrade the weld quality level for that particular position. Figure 11 gives a schematic illustration of the Graphical User Interface (GUI) for the ONWELD system.

\subsection{ONWELD—measurement system analysis}

In order to test how reliable the ONWELD system is, repeatability tests were conducted. Welded samples were scanned

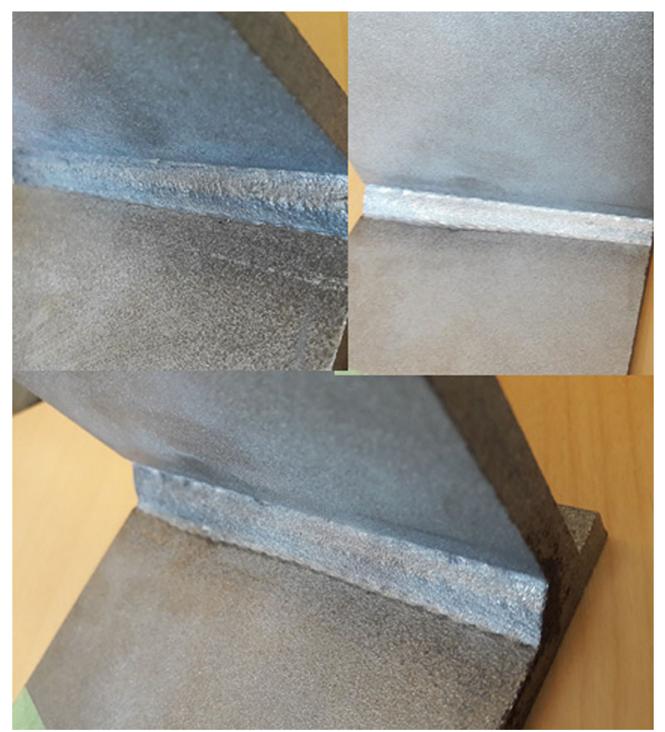

Fig. 12 Some welded test samples that were scanned multiple times to test repeatability with $100 \mathrm{~Hz}$ three times, resulting in more than 600 measurements each time for each sample. Figure 12 shows three representative samples with different weld geometry where the welded specimens do show undercuts at the weld toe, changing throat thickness, etc. Compared to a similar study conducted 1 year before, several improvements were noticed, e.g., lower sensitivity to vibrations and reduced number of returned error values $(-1)$.

Since the connection to the exact position was not yet available in this actual test system, the start position for the measurements had to be estimated based on when the system returned measurements (on the weld) instead of error values (outside the weld). This can be a source of errors in the case the estimated start positions are not exactly the same between the samples.

The variation stemming from the measurement system varied depending on the property monitored. Figure 13 shows the results when scanning the weld sample three times. The variation and scatter in the results are small for the throat size measurements which illustrate the repeatability potential of the system. As an example, Fig. 14 shows the Gauge $R \& R$ for the left transition radius for test part 1 where the range average, the difference between the measured results for each measuring point, was $0.283 \mathrm{~mm}$. More than $30 \%$ of the variation in the measurement system for this property was stemming from the measurement system itself. When instead measuring throat thickness, as displayed in Fig. 15, the range average was only $0.036 \mathrm{~mm}$ and the variation stemming from the measurement system was only $1.5 \%$. Table 2 shows the range average for the different properties/ imperfections when six test parts and a test block were 
Fig. 13 The left transition radius result when scanning the welded samples three times

\section{Scatterplot of Outer Transition radius - Left vs measuring point}

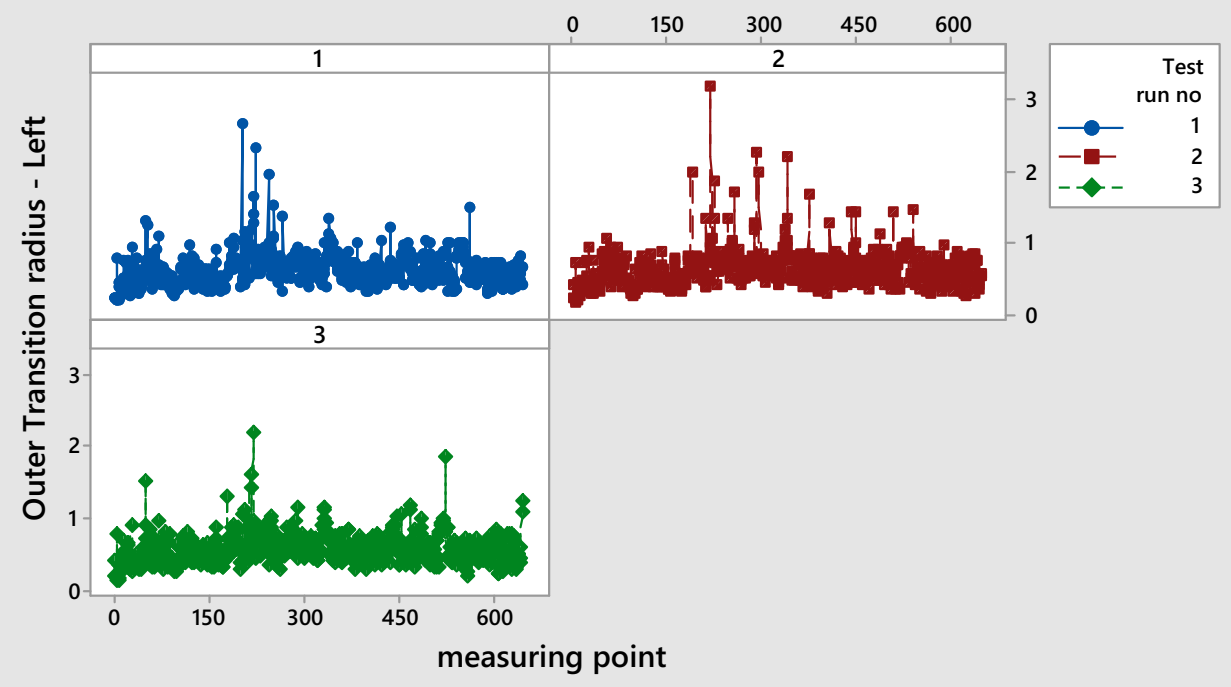

Panel variable: Test run no

\section{Gage R\&R (ANOVA) Report for Outer Transition radius - Left}

Gage name: Part 1

Reported by: Anna Ericson Öberg

Date of study: 2016-10-10
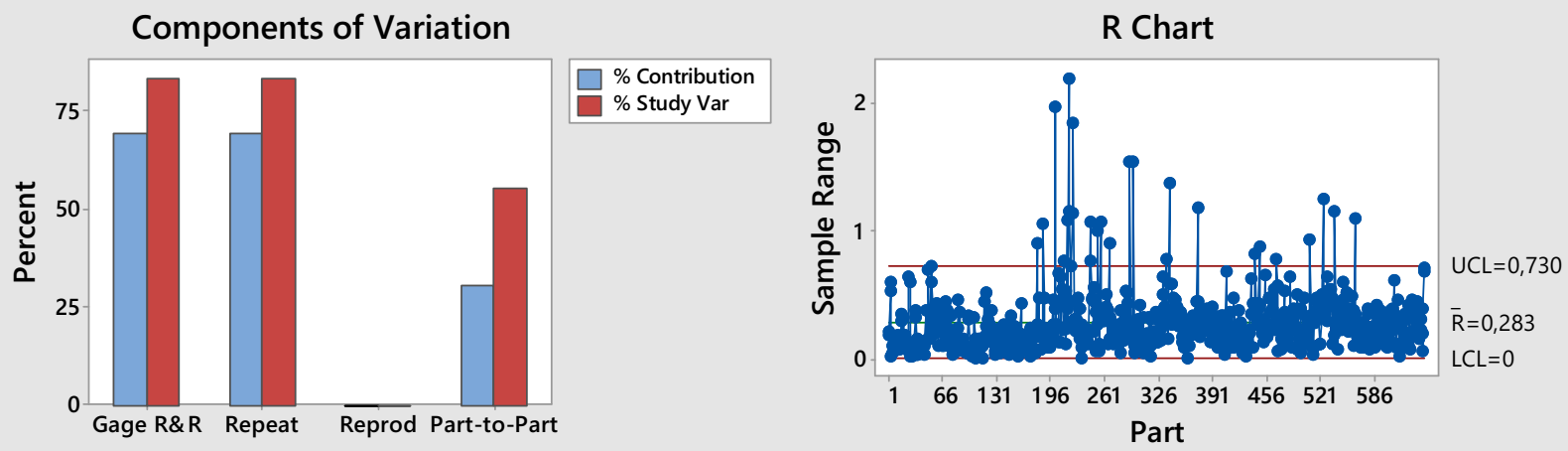

Outer Transition radius - Left by measuring point

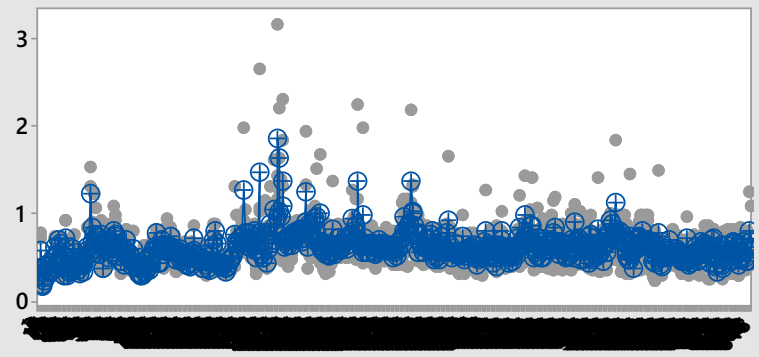

measuring point

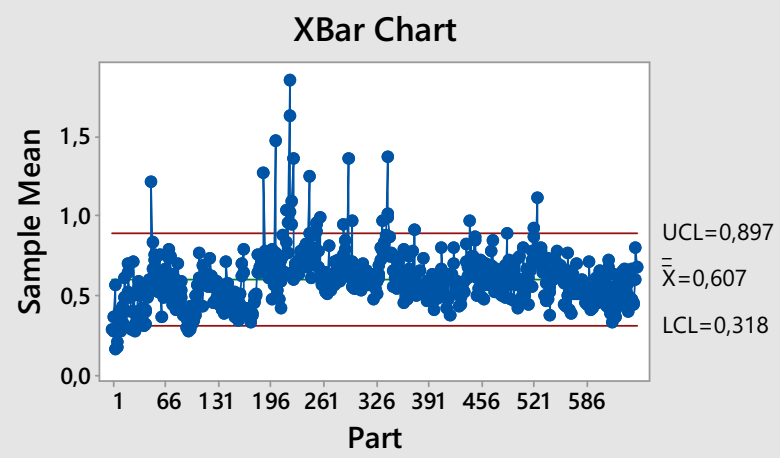

Fig. 14 Gauge R\&R for the left transition radius for part 1 


\section{Gage R\&R (ANOVA) Report for Throat Thickness [mm]}

\section{Gage name: Part 6 MSA Throat thickness Date of study: $\quad$ 2016-10-10}

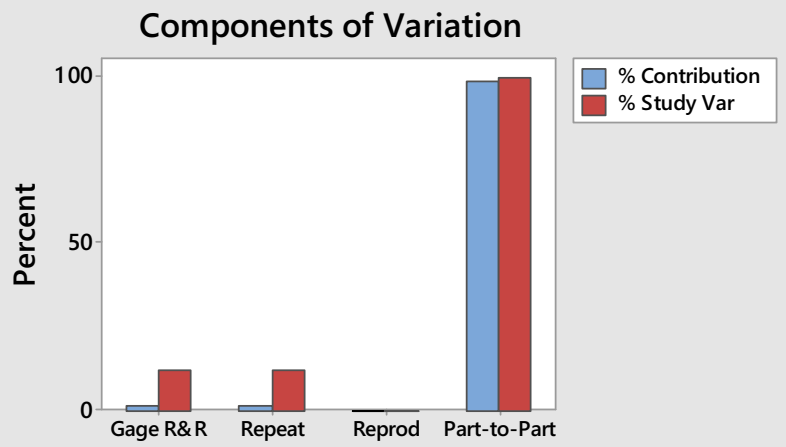

Throat Thickness [mm] by measuring point

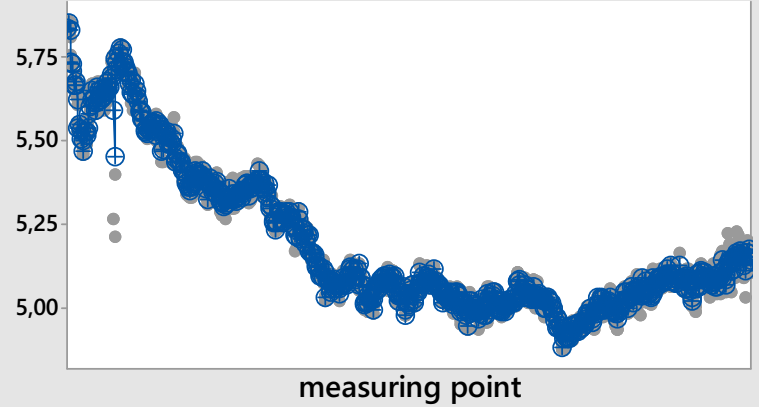

Reported by: Anna Ericson Öberg
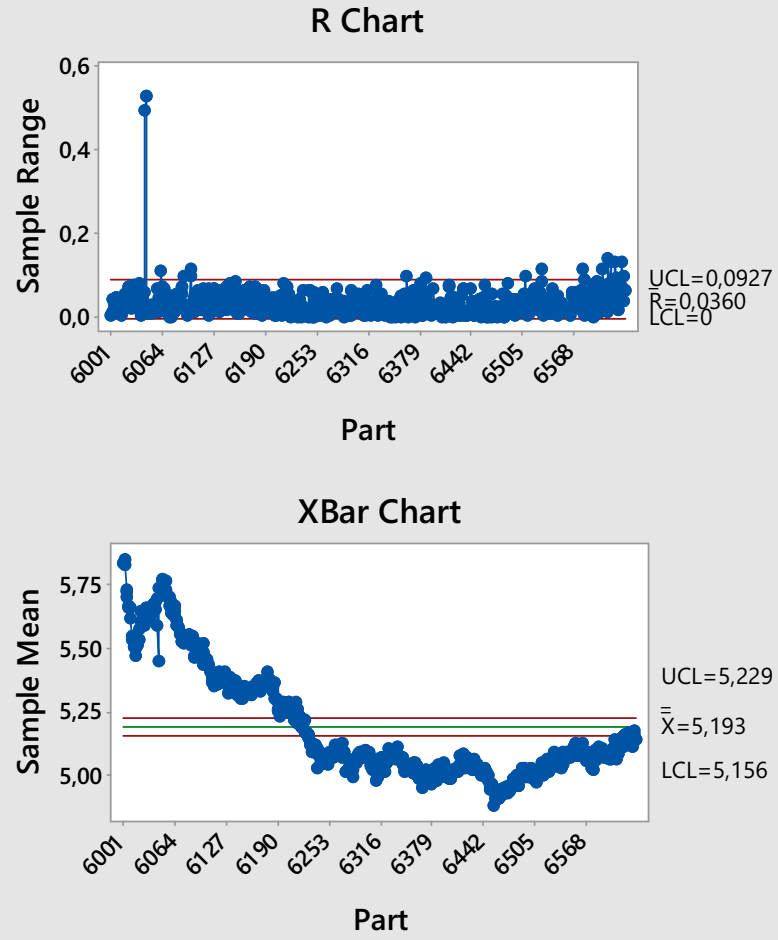

Fig. 15 Gauge R\&R for throat thickness test for part 6

Table 2 Range average for the different properties/imperfections

\begin{tabular}{ll}
\hline Property/imperfection & Range average \\
\hline Throat size & $0.139 \mathrm{~mm}$ \\
Transition radius (left/right) & $0.674 \mathrm{~mm} / 0.760 \mathrm{~mm}$ \\
Leg deviation (left/right) & $0.075 \mathrm{~mm} / 0.129 \mathrm{~mm}$ \\
Plate angle & $0.359^{\circ}$ \\
Undercut (left/right) & $0.087 \mathrm{~mm} / 0.085 \mathrm{~mm}$ \\
\hline
\end{tabular}

Fig. 16 Scanning of fillet weld, butt weld, and impression

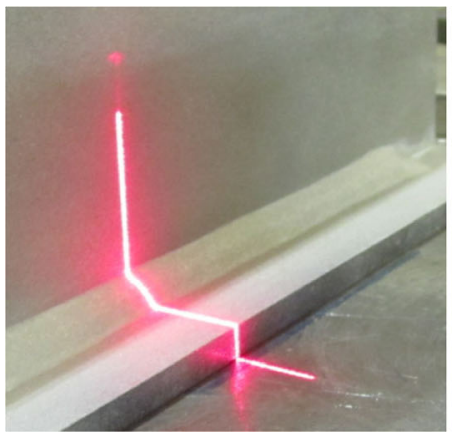

scanned. The major challenge for the system is to measure the transition radius.

\subsection{Future development of ONWELD system}

The ONWELD system have been tested and verified on various welded joints, e.g., fillet welds and butt welds, as well as impressions, to cover the most frequent weld imperfections
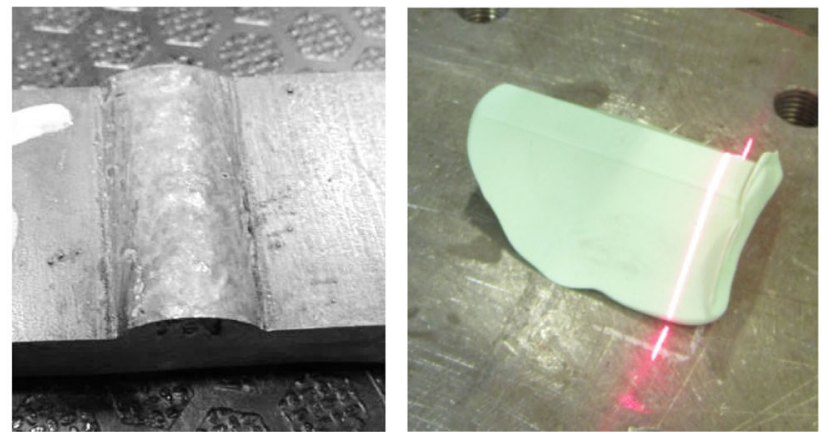
Fig. 17 ONWELD system; future application for welding process optimization

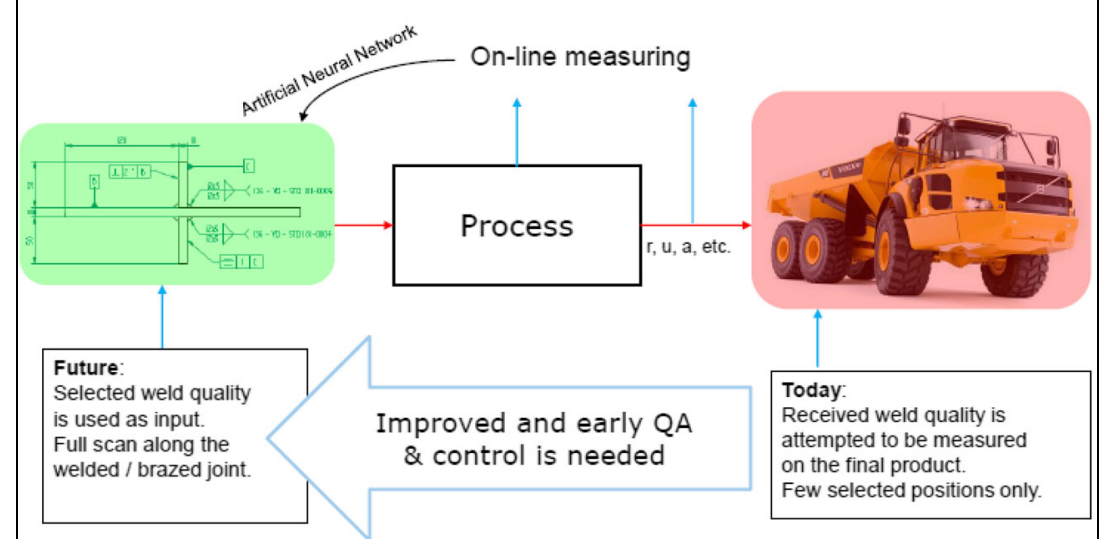

included in the different weld quality standards; Fig. 16 shows examples of such scanning. The tests show that it is possible to measure the weld geometry and verify the weld class which has a direct link to the fatigue properties of the welded joint. The most difficult property to measure is transition radius. An improvement in range average can be expected when the robot positions can be accurately attained to make sure the exact same position is evaluated every time.

The next step in the development of the ONWELD system is to use the measurement data for the weld joints for rapid feedback on how the weld quality is influenced by different setups of the welding parameters such as current, voltage, wire feed rate, travel speed, and gun angle. This will enable an adjustment of the welding process parameters in situ to achieve the required weld quality system during the production. Figure 17 illustrates the conceptual future application of the ONWELD system where the feedback communication can be used for optimizing the welding process to achieve weld quality required.

\section{Conclusions}

Weld quality assurance and control is an integral part for the development of optimization of welded structures subjected for fatigue loading in order to achieve increase in the durability and reduce variation for a sustainable production. To create a framework for efficient fabrication of welded structures subjected to fatigue, it is necessary to pass the following steps:

- Identify critical points of the welds which set the fatigue life of the welded structure

- Develop welding procedures to optimize the fatigue properties of the weld in relation to the load conditions. This means improved properties at the weld toe or at the weld root.

- Define appropriate weld requirements which contribute to a high focus on critical characteristics, merging best knowledge of the welding process, fatigue properties and the weld requirements

- Set design rules for the improved welding procedures to connect the expected fatigue properties of the weld and the design limits

- Use the new requirements and design guideline to design structures which are optimized for both cost and fatigue

The concept of design for purpose could be adopted by using the ONWELD system and focusing on quality assuring the critical weld toe based on the knowledge on how the welds in the structure are loaded which in return would result in a cost-effective quality control.

The current international standards for weld quality criteria are mostly based on workmanship rather than the effect of weld quality on the structural performance of the structure, e.g., fatigue properties. However, recent development of weld quality systems enables a link between acceptance criteria, quality levels, and the fatigue strength [1,2]. Furthermore, high weld quality levels, with high requirements on the acceptance criteria for the weld imperfection, in order to increase the overall performance and quality of the structures, might not be fulfilled due to the difficulties of control and assurance. Most of the quality control and inspection measurement tools used today in welding production are handheld and the measurements results in large unreliable scatter where the repeatability is poor. One approach to reduce the amount of unnecessary quality control of welds is to adopt the concept of "weld for purpose," that is the weld is dimensioned and produced to have the correct weld quality requirements based on, e.g., the loading and the environment it is subjected to.

Within the scope of the research work reported herewith, a new system has been developed, ONWELD (ONline method for quality assurance of WELDed structures) with hardware and software to assess the weld quality of fillet, overlap, and butt welds. The system shows acceptable variation of continuous scanning of weld toe radii of $0.5 \mathrm{~mm}$ and a slightly larger variation at weld toe radii around $1 \mathrm{~mm}$. The system is also capable of continuous measurement of the weld throat 
thickness with a small variation of $3.5 \%$ variation and weld undercuts with a variation of $17 \%$. The system enables a significantly improved weld quality assurance which will lead to a more optimized design and a more robust and sustainable manufacturing.

Acknowledgements The funding agency VINNOVA under the FFI program Sustainable Production is acknowledged for public funding. The involved companies (Volvo Group, GKN Aerospace, ABB Robotics, Väderstad, and ESAB) are acknowledged for the industrial financial support.

Open Access This article is distributed under the terms of the Creative Commons Attribution 4.0 International License (http:// creativecommons.org/licenses/by/4.0/), which permits unrestricted use, distribution, and reproduction in any medium, provided you give appropriate credit to the original author(s) and the source, provide a link to the Creative Commons license, and indicate if changes were made.

\section{References}

1. Volvo Group (2013) BSTD181-0004; Available Online. https:// webstd.volvo.com/webstd/docs/181-0004

2. Hobbacher A (2009) IIW recommendations for fatigue design of welded joints and components, vol 520. WRC, Welding Research Council Bulletin, New York

3. ISO/TC 44/SC 10 (2011) ISO 5817:2007, welding - fusion-welded joints in steel, nickel, titanium and their alloys - quality levels for imperfections. SIS

4. Barsoum Z, Jonsson B (2011) Influence of weld quality on the fatigue strength in seam welds. Eng Fail Anal 18(10):971-979

5. Karlsson N, Lenander PH (2005) Analysis of fatigue life in two weld class systems, master thesis in solid mechanics, LITH-IKPEX-05/2302-SE. Linköping University, Sweden

6. Barsoum Z, Samuelsson J, Jonsson B, Björkblad A (2012) Fatigue design of lightweight welded vehicle structures: influence of material and production procedures. J Engineering Manufacture 226(10):1736-1744

7. Hammersberg P, Olsso H (2010) Statistical evaluation of welding quality in production. In: Barsoum, Z. (ed.) Proceedings of Swedish Conference on Lightweight Optimised Welded Structures, Borlänge, Swede. 148-162

8. Shafeek HI, Gadelmawla ES, Abdel-Shafy AA, Elewa IM (2004) Automatic inspection of gas pipeline welding defects using an expert vision system. NDT\&E International 37(4):301-307

9. Wu JH, Chang RS, Jiang JA (2007) A novel pulse measurement system by using laser triangulation and a CMOS image sensor. J Sensors 7:3366-3385
10. Huang W, Kovacevic R (2011) A laser-based vision system for weld quality inspection. J Sensors 11(1):506-521

11. Bhatti AA, Barsoum Z, Murakawa H, Barsoum I (2015) Influence of thermo-mechanical material properties of different steel grades on welding residual stresses and angular distortion. Journal of Materials \& Design 65:878-889

12. Bhatti AA, Barsoum Z, van der Mee V, Kromm A, Kannengiesser T (2013) Fatigue strength improvement of welded structures using new low transformation temperature filler materials. Procedia Engineering 66C:192-201

13. Barsoum Z, Jonsson B (2011) Influence of weld quality on the fatigue strength in seam welds. Eng Fail Anal (18):971-979

14. Shaw R (2011) Comparison of ISO 5817 quality criteria to that of national standards - surface imperfections. International Institute of Welding Doc. XIII-2392-11 www.iiwelding.org

15. Barsoum Z, Jonsson B (2008) Fatigue assessment and LEFM analysis of cruciform joints fabricated with different welding processes. Welding in the World 52(7/8):93-105

16. Jonsson B, Samuelsson J, Marquis G (2012) Development of weld quality criteria based on fatigue performance. Welding in the World 56(11):153-169

17. Marquis G (2010) Failure modes and fatigue strength of improved HSS welds. Engineering Fracture Mechanics, Engineering Fracture Mechanics 77(11):2051-2062

18. Jonsson B, Dobmann G, Hobbacher AF, Kassner M, Marquis G (2016) IIW guidelines on weld quality in relationship to fatigue strength. Springer, IIW Collection. www.springer.com

19. Niemi E, Fricke W, Maddox S (2006) Fatigue analysis of welded components / designers guide to hot spot stress approach, IIW doc XIII-1819-00/XV-1090-01 update 2003. Woodhead Publishing, UK

20. Fricke W (2012) IIW Recommendations for the Fatigue Assessment of Welded Structures by Notch Stress Analysis, IIW2006-09, Woodhead Publishing Ltd, ASIN: B013PT3NYW, https://www.elsevier.com/books/iiw-recommendations-for-thefatigue-assessment-of-welded-structures-by-notch-stress-analysis/ fricke/978-0-85709-855-9

21. Åstrand E (2015) A new innovative toolbox for lean welding of fatigue loaded structures. Int J Adv Manuf Technol 81(1):635-643

22. Ericson Öberg A (2016) Predictability - an enabler of weld production development. Doctoral thesis, Chalmers University of Technology,

23. Drosos K, Kotsakis S (2014) Influence of welding parameters on weld quality and productivity using metal cored wires, Master Thesis, Chalmers University of Technology, Gothenburg

24. Öberg AE, Hammersberg P (2016) Facilitating decision-making by choosing an NDT method based on information need. Weld World 60(5)979-985 